\title{
NANOTECNOLOGIA E SUA REGULAMENTAÇÃO NO BRASIL
}

NANOTECHNOLOGIES AND ITS REGULATIONS IN BRAZIL

\section{Luísa Lauermann Lazzaretti}

Especialista em Gestão Empresarial pela ESPM. Graduada em Direito pela Universidade Feevale. Graduada em Farmácia pela Universidade Federal do Rio Grande do Sul.

E-mail: lulilazzaretti@gmail.com.

\section{Haide Maria Hupffer}

Pós-Doutora em Direito e Doutora em Direito pela Unisinos. Docente e Pesquisadora do Programa de Pós-Graduação em Qualidade Ambiental e do Curso de Direito da Universidade Feevale. Líder do Grupo de Pesquisa Direito e Desenvolvimento CNPq/Feevale.

E-mail: haide@feevale.br. 


\section{RESUMO}

O presente estudo objetiva contextualizar a formação de um conceito para nanotecnologias, suas potencialidades, seus benefícios e examinar a legislação brasileira sobre nanotecnologia e as propostas do legislativo para sua regulamentação. 0 estudo é de caráter exploratório e descritivo com apoio no método sistêmico-construtivista para contextualizar as nanotecnologias no sistema econômico e no sistema do Direito, seus riscos e benefícios. A pesquisa aponta que não há uma regulação específica para as nanotecnologias no Brasil, a exemplo da maioria dos países. Regular as nanotecnologias é um dos maiores desafios do sistema político, jurídico e econômico, considerando as peculiaridades das características físicoquímica dos nanomateriais, seus potenciais riscos e seu interesse comercial. A nível mundial, observa-se que organizações internacionais privadas implementaram estratégias de autorregulação mais voltadas para boas práticas e que desempenham uma função importante na regulação das nanotecnologias, as quais, mesmo tendo aplicações volitivas pelas empresas e pelos governos, são bem aceitas por eles e bem vistas pelos consumidores.

Palavras-chave: Nanotecnologia. Regulamentação. Autorregulação.

\section{ABSTRACT}

The presentstudy aims to contextualize the formation of a concept for nanotechnologies, their potentialities, their benefits and to examine the Brazilian legislation on nanotechnology and the legislative proposals for its regulation. The study is exploratory and descriptive with support of the systemic-constructivist method to contextualize nanotechnologies in the economic system and in the legal system, its risks and benefits. The research points that there is not a specific regulation for nanotechnologies in Brazil, such as most countries. Regulating nanotechnologies is one of the major challenges of the political, legal and economic system, considering the peculiarities of the nanomaterials' physico-chemical characteristics, their potential risks and their commercial interest. At the global level, it is possible to observe that private international organizations have implemented self-regulation strategies more focused on good practices, and, that has an important role in nanotechnologies' regulation, which, even if it is volitional applied by companies and governments, it is well accepted by them and well seen by the consumers.

Keywords: Nanotecnologia. Regulamentação. Autorregulação. 


\section{INTRODUÇÃo}

A nanotecnologia consiste na aplicação de insumos ou processos em que ao menos um de seus componentes possua uma de suas dimensões na escala nanométrica, ou seja, entre um e 100 nanômetros, propiciando a manipulação de qualquer material reduzido a essa escala, surgindo novos materiais em qualquer área econômica, influenciando a economia mundial. Muitos estudiosos consideram essa tecnologia como constituinte da Quarta Revolução Industrial, pois essa tecnologia faz parte de uma evolução tecnológica tão significativa que representa, juntamente com outras tecnologias, alterações históricas inimagináveis como em relação ao tamanho diminuto, à velocidade do desenvolvimento dessas novas tecnologias e ao elevado grau de complexidade devido aos diferentes agentes envolvidos nesse processo, como as universidades, pesquisadores, fabricantes, governos e a sociedade em geral, através de grupos de interesses.

Nanoprodutos já estão disponíveis no mercado consumidor em larga escala e, consequentemente, há um crescimento da exposição à essa tecnologia tanto por parte dos pesquisadores, trabalhadores quanto dos consumidores. Ademais, esses produtos são utilizados e descartados em diferentes ambientes sem o devido controle e regulamentação, podendo causar graves problemas às presentes e futuras gerações.

O principal objetivo do presente artigo é observar como está a regulação e a normatização de produtos e aplicações com nanotecnologia no Brasil, principalmente em relação à caracterização dos nanomateriais, à indicação na rotulagem desses produtos e políticas de pesquisa, desenvolvimento e comercialização das nanotecnologias. Como objetivos específicos, será conceituada a nanotecnologia e a nanociência, descritas suas potencialidades, benefícios, riscos, investimentos em pesquisa e o mercado internacional e brasileiro nanotecnológico.

O estudo é de caráter exploratório e descritivo com apoio no método sistêmico-construtivista para contextualizar as nanotecnologias no sistema econômico e no sistema do Direito, seus riscos e benefícios.

\section{NANOCIÊNCIA E NANOTECNOLOGIA: DEFINIÇÕES E NOMENCLATURAS}

O prefixo "nano" tem origem etimológica grega e significa anão. Esse termo indica dimensões físicas que estão na ordem de um bilionésimo de qualquer unidade de medida, por exemplo, o nanômetro, unidade de medida utilizada na nanotecnologia, tem $10^{-9}$ metros $(\mathrm{m})$, sendo, essa escala, coloquialmente conhecida por escala nanométrica ou ainda nanoescala. Igualmente, o vocábulo tecnologia é derivado do grego e é definido como a utilização do método científico com objetivos práticos e comerciais. (MEDEIROS; MATTOSO, 2006). 
Um nanômetro é uma medida tão pequena que é difícil de visualizá-la sem equipamentos específicos, a título de exemplo, a cabeça de um alfinete é um milhão de nanômetros (nm); um fio de cabelo é 100.000 nm; o tamanho da maioria das bactérias gira em torno de 1.000 a 5.000 nm; os vírus, em média, têm de 100 a 500 nm; e o Ácido Desoxirribonucleico (DNA), que é o nosso material genético, é de um a dois nm, ou seja, a nanotecnologia é a escala do nosso DNA e de outras biomoléculas, como os carboidratos, lipídios e os ácidos nucléicos. (SHATKIN, 2013).

Entretanto, nem todos os materiais que estão na escala nanométrica são definidos como nanotecnologia. Existem nanopartículas que ocorrem no meio ambiente, geradas naturalmente ou através da atividade metabólica dos seres vivos. Os animais utilizam essas nanopartículas naturais como os açúcares, as proteínas e outras biomoléculas em processos bioquímicos. Muitas nanopartículas são encontradas livremente na natureza, como nanocristais contidos na teia de aranha, no azul das asas das borboletas, geradas após a interferência da luz na ordenação das asas em escala micro e nanométrica, bem como nas patas das lagartixas que são revestidas de pelos finíssimos que podem se aproximar e fixar em uma base de apoio a uma distância de poucos nanômetros, permitindo caminharem sobre as superfícies como as paredes. Ressalta-se que as nanopartículas também podem ser geradas nos processos de combustão, como, por exemplo, no ar poluído e nas cinzas vulcânicas. (NNI, 2008).

Consoante a organização National Nanotechnology Initiative (NNI), a nanotecnologia consiste na habilidade de estudar, de entender e de desenvolver materiais em dimensões entre um e 100 nanômetros, possibilitando novos usos para materiais já conhecidos comercialmente. (NNI, 2013). Entretanto, a fundação National Science Foudation (NSF) delineia a nanotecnologia de modo mais abrangente, pois considera que a manipulação a nível atômico pode ocorrer, também, abaixo de um nanômetro ou acima de 100 nanômetros, principalmente nos nanomateriais poliméricos de dimensões entre 200 a 300 nm. Essas partículas poliméricas se destacam em virtude das suas interações intermoleculares, sendo seu uso evidente nas áreas farmacêuticas e médicas. (ABDI, 2013).

A Comunidade Europeia anunciou recomendações para a descrição de nanomateriais em 2011, considerando um nanomaterial tanto aquele de origem natural quanto o incidental ou manufaturado que contém partículas em estado não ligado, aglomerado ou agregado, com no mínimo 50\% das partículas entre $100 \mathrm{~nm}$. Porém, esse limiar pode ser modificado para 50\% do material composto por partículas de até 100 nm, se necessário, mas com a necessária aplicação do princípio da precaução ao meio ambiente, à segurança, à saúde ou mesmo à competitividade comercial. O conceito definido pela European Medicine Agency (EMA) também considera como nanotecnologia estruturas menores de 1.000 nm de diâmetro com propriedades específicas diferentes da matéria em escala maior e adota critérios semelhantes à Comissão Europeia (ABDI, 2013). Salienta-se que a fundação não governamental International Risk Governance Council 
(IRG) aconselha o uso da definição de nanotecnologia e de nanomateriais estabelecida pela International Organization for Standardization Technical Committee (ISO/TC) 229 de 2005 e a Techinical Specifications (ISO/ TS) 27687 de 2008 para serem utilizados na área alimentícia e cosmética (IRG, 2009).

O estudo da nanoescala é importante, posto que as propriedades físico-químicas dos materiais tendam a ser diferentes das propriedades do mesmo material em larga escala, devido ao aparecimento de efeitos quânticos de tamanho e fenômeno de superfície. Assim, um elemento, quando reduzido à escala nanométrica, pode apresentar propriedades eletrônicas, mecânicas, térmicas, ópticas diversas, quando comparado com seu natural (estendido). Esta alteração nas propriedades fundamentais com a variação do tamanho das partículas é denominada de efeito do tamanho. (LOOS, 2014).

Além disso, a redução das partículas em escala nanométrica ocasiona uma consequência importante para a funcionalidade dos nanomateriais queé o aumento daárea superficial nessas matérias nanoscópicas, devido ao aumento significativo da quantidade de átomos superficiais quando comparado com o volume total da partícula, modificando, assim, sua reatividade química e sua funcionalidade. (MARTINEZ; ALVES, 2013).

Essas propriedades que os elementos apresentam em nanoescala são importantes, visto que oferecem uma vasta faixa de novas aplicações, novos materiais e novas tecnologias para serem compreendidos pela nanociência. Ainda, essa propriedade única permite que menos material seja utilizado na síntese de um produto, pois há um aumento da área superficial, aumentando a reatividade, permitindo preservar os recursos naturais como a energia e reduzir os custos de produção, portanto, geram-se benefícios tanto para o meio ambiente quanto para a economia. (SHATKIN, 2013).

Um exemplo disso é o estudo e a manipulação do elemento ouro em escala nanométrica. O ouro em seu estado original, estendido, reflete a luz através de sua superfície e possui coloração amarelada, contudo, quando se apresenta em estado de nanopartículas, absorve alguns comprimentos de onda de luz, alterando sua coloração para vermelha, verde e magenta, dependendo do tamanho da partícula. Outro exemplo que se observa com o efeito de tamanho das partículas sobre as propriedades é a temperatura de fusão do ouro, pois, quando na forma estendida, é de $1063^{\circ} \mathrm{C}$, entretanto, quando as partículas são de dois nm, a temperatura de fusão diminui para $500^{\circ} \mathrm{C}$, uma diferença de mais de $500^{\circ} \mathrm{C}$. Essas alterações no elemento ouro propiciaram um maior espectro de utilização, podendo, inclusive, utilizar as nanopartículas de ouro combinadas com biomoléculas nos exames de diagnósticos médicos. (MARTINEZ; ALVES, 2013).

Os produtos sintetizados por meio da nanotecnologia podem ser divididos em quatro diferentes gerações definidas por Roco et al. em 2006. A primeira geração constitui-se de produtos sintetizados antes do ano 2000, são exemplos desse grupo os revestimentos nanoestruturados, dispersão de nanopartículas, superfícies nanopadronizadas e materiais in natura (matérias-primas), como os metais 
nanoestruturados. Os materiais dessa geração possuem estruturas estacionárias. A segunda geração de produtos nanotecnológicos é composta por nanoestruturas ativas, como novos transistores, fármacos alvo e produtos químicos; a síntese dessas substâncias deu-se a partir de 2005. Já, após 2010, tem-se o início da terceira geração que se identifica pelo uso de sínteses e técnicas de montagem, como robótica, biomontagem e em multiescala, relacionados com nanosistemas baseados em mecânica quântica. Enquanto que a quarta geração, segundo os pesquisadores, iniciar-se-á entre os anos de 2015 e 2020 e englobará nanosistemas moleculares heterogêneos em que cada molécula tem uma estrutura específica, desempenhando um papel diferente. (ROCO et al., 2011).

A sintese de nanomateriais envolve basicamente dois processos: o top-down e o bottom-up. 0 processo top-down (de cima para baixo) consiste na síntese de estruturas em nanoescala, a partir de outras em escala maior, utilizando-se processos físicos, como, por exemplo, as nanopartículas de submícron, geradas por processo de moagem da matéria em escala normal até a obtenção de partículas muito pequenas. Ademais, o método top-down é o mais comum, sendo realizado a seco. A luz é empregada para realizar gravações de padrões, sendo essa técnica empregada na produção de chips. Já no método bottomup, que significa de baixo para cima, a síntese ocorre através da montagem do nanomaterial átomo por átomo ou molécula por molécula. Geralmente esse é um processo químico, realizado, principalmente, via úmida, ou seja, utilizam solventes, através de síntese envolvendo processos químicos, entretanto, também pode ser realizado por processos físicos através de potentes microscópios. (MARCONE, 2015).

As partículas nanométricas apresentam instabilidade térmica, apresentando naturalmente a tendência de se agregarem, formando complexos estruturais maiores, ocasionando possivel perda ou diminuição de suas propriedades advindas da nanoescala. Esse fator de agregação é um desafio para os pesquisadores, e uma das alternativas disponiveis para a síntese de formulações nanotecnológicas mais estáveis é observar as características de biodegrabilidade, biocompatibilidade, capacidade para funcionalização da superfície da partícula, conjugação, complexação e encapsulamento desses materiais. Os nanomateriais utilizados pela indústria são geralmente encapsulados como forma de proteção à degradação pela luz, pelo oxigênio, para estabilidade do composto, para aumentar a solubilidade e para evitar sedimentação do nanomaterial. A título de exemplo, alguns métodos de encapsulamento são a solubilização ou a retenção na nanopartícula, a conjugação ou a adsorção. (ZARBIM, 2007; DIMER et al., 2013).

As nanopartículas poderão ser classificadas, conforme sua composição química, em três grandes grupos: as nanopartículas inorgânicas, as orgânicas e as híbridas, sendo a classificação mais utilizada no meio acadêmico. No grupo das inorgânicas, destacam-se os óxidos metálicos, como dióxido de titânio, óxido de ferro, as nanopartículas dos metais de transição, como o ouro e a prata, e os pontos quânticos 
compostos, principalmente, por cádmio e selênio. No grupo das orgânicas, as principais representantes são as nanopartículas formadas pelos átomos de carbono, como o fulereno, os grafenos e as nanofibras de carbono, além dos lipossomas, nanoemulsões, dentre outras. Já os nanomateriais híbridos são formados por dois tipos de nanocomponentes com funções complementares ou coesas entre si, como exemplo, elenca-se a conjugação de biomoléculas a nanopartículas metálicas e a associação de nanomoléculas orgânicas a matrizes nanopoliméricas com a finalidade de melhorar as propriedades térmicas, mecânicas e ópticas. (COSTA, 2015).

A inovação trazida pelo desenvolvimento da tecnologia em nanoescala originou uma revolução tecnológica e industrial marcante, ocasionando modificações nas relações de consumo. Além disso, a nanotecnologia destaca-se pela possibilidade de utilizar como matérias-primas todos os elementos da tabela periódica (disposição dos elementos químicos em uma tabela divididos por períodos e grupos, organizados por afinidade química, em ordem crescente de número atômico, pela configuração eletrônica), possibilitando o seu uso em quase todos os produtos manipulados, abrangendo praticamente todos os setores industriais (BUSSINGER; TOSE, 2017).

Logo, a nanotecnologia destaca-se pela multidisciplinaridade, pois seu estudo relaciona áreas da física, química e biologia, podendo-se concluir que é a real potencialidade dessa nova tecnologia, enquadrando-se no grupo das tecnologias convergentes, já que há interação e combinação cooperativa entre diferentes áreas de conhecimento, como a tecnologia da informação, a medicina, a neurociência cognitiva e a biotecnologia. Isso tudo possibilitou o emprego da nanotecnologia em todos os setores industriais de produção, modificando de forma revolucionária as técnicas de síntese e manufatura na indústria médica, de higiene e beleza, gestão ambiental e da tecnologia da informação, impactando tanto as relações sociais, políticas e ambientais, quanto as relações com os consumidores (BUSSINGER; TOSE, 2017).

\section{NANOTECNOLOGIAS: MERCADO, BENEFÍCIOS E RISCOS}

O mercado da nanotecnologia é altamente promissor. Em 10 de dezembro de 2018, o site da StatNano divulgou que já são comercializados 8.523 nanoprodutos, produzidos por 2.084 companhias em 59 países (StatNano, 2018). Novos produtos e aplicações com nanotecnologia são lançados em praticamente todas as áreas e em velocidade crescente. Entre os dez principais setores com produtos e aplicações com nanotecnologia, o campeão em nanoprodutos é o setor eletrônico, que já disponibilizou no mercado consumidor 2.050 produtos, seguido da área de medicina com 972, cosméticos com 780, setor têxtil 
com 696, construção civil com 645, automotivo com 539, meio ambiente com 526, energias renováveis com 467, setor de alimentação com 335 e setor petroquímico com 302 produtos nanoengenheirados. (StatNano, 2018).

A nanotecnologia é uma realidade presente em inúmeros produtos e aplicações comercializados por diferentes setores econômicos movimentando cerca de 4 trilhões de dólares no mundo no ano de 2018. Empresas e governos investem bilhões em pesquisa e desenvolvimento de nanotecnologias no mundo. Países como Estados Unidos da América e o Canadá são os que mais investem nesse setor. Só na área da saúde, o mercado mundial de produtos faturou cerca de 160 bilhões de dólares em 2015. Comparado com outros países, o investimento no Brasil é mais modesto. Barbosa, Bagattolli e Invernizzi (2018, p. 62) realizaram um mapeamento de todos os projetos aprovados com recursos não reembolsáveis da Financiadora de Estudos e Projetos (FINEP) no período de 2006 até 2016 e registraram que a FINEP "concedeu R\$ 81,29 milhões para 56 projetos em Nanotecnologia no período, e as empresas aportaram como contrapartida um valor médio de $\mathrm{R} \$ 1,45$ milhão por projeto, cobrindo $60,2 \%$ do valor total dos mesmos (considerando o valor concedido mais contrapartidas das empresas) que ascendeu a $\mathrm{R} \$ 134,83$ milhões". O maior volume de recursos disponibilizado pela FINEP foi no ano de 2007. Chama a atenção no estudo realizado que, no período de 2014 até 2016, não foram lançados editais ou projeto especificamente para o desenvolvimento de pesquisas com nanotecnologia, o que revela "falta de priorização sustentada da NT neste instrumento estratégico de promoção da inovação" (BARBOSA; BAGATTOLLI; INVERNIZZI, 2018, p. 62).

Ainda, conforme um ranking realizado pela StatNano (2017a), o qual posicionou os dez principais países que mais depositaram patentes em 2017, os Estados Unidos da América ocupam o primeiro lugar, correspodendo a 51,7\% das patentes da United States Patents and Trademark Office (USTPO) e 34, 20\% das patentes da European Patent Organization (EPO). A Coreia do Sul e o Japão ocupam, respectivamente, o segundo e o terceiro lugares. Já no Brasil, no ano de 2017, foram depositadas 14 patentes nanotecnológicas pela USTPO e 6 pela EPO. (StatNano, 2017a).

O grupo StatNano (2017b) publicou um relatório realizado em janeiro de 2018 no qual foi analisada a quantidade de artigos sobre nanotecnologia indexados na base de dados Wef of Science em 2017 por países. Ao todo foram 154.000 artigos indexados nessa base de dados. Aproxidamente $52 \%$ dessas publicações foram realizadas por três países: China, EUA e Índia. Quando agrupa-se os cinco países que mais publicaram em 2017, China, EUA, Índia, Iran e Coréia, observa-se que esses países respondem a $62 \%$ de todos os artigos indexados na Web of Science. Nos últimos anos, a China tem ocupado o primeiro lugar no ranking dos países que mais publicaram trabalhos científicos com 56.000 artigos, seguido dos Estados Unidos da América com 24.000 artigos. O Brasil ocupa a $17^{\circ}$ posição com 2.788 trabalhos 
publicados, correspondendo a 5,7\% do total de artigos indexados em 2017 (StatNano, 2017b). Em 2016, 0 Brasil também ocupava a $17^{\circ}$ posição com 2.471 artigos indexados na base de dados da Web of Science, correspondendo a 1,8\% do total de artigos publicados nessa base. (StatNano, 2017c).

A nanotecnologia é uma tecnologia muito promissora para a indústria farmacêutica, biotecnológica e biomédica, considerada por muitos estudiosos uma das tecnologias que integram a Quarta Revolução Industrial, pois tem propiciado o desenvolvimento de novos medicamentos baseados em nanoestruturas complexas altamente seletivas, além de ser uma esperança no desenvolvimento de novos produtos para a medicina, principalmente máquinas moleculares (nanobots, sondas, sensores) que propiciam novos métodos de diagnóstico precoce para o câncer (capacidade de observação de células individuais, rastreamento do movimento de células cancerosas, rastreamento de moléculas individuais que se movem no entorno das células cancerosas), enfermidades infecciosas, terapia e sistemas para a administração de fármacos; nanosensores que circulam dentro do corpo para monitorar níveis de colesterol, hormônios e glicose, entre outros benefícios. Também, possibilitou a elaboração de cosméticos com maior poder de absorção e estabilidade, medidores de níveis de glicose, tintas com poderes abrasivos, ação bactericida e fungicida, além de suplementos alimentares. Outra meta ambiciosa é o desenvolvimento da medicina personalizada, regenerativa e teranóstica (ALVES, 2004; ABDI, 2013; LONDANO, 2015).

A nanotecnologia está presente em toda a cadeia produtiva da indústria alimentícia na qual nanopartículas ou técnicas de nanotecnologia são utilizadas desde o cultivo dos alimentos na agricultura, processamento e, posteriormente, em embalagens. Na agricultura, a promessa das nanopartículas engenheiradas são para ampliar o rendimento da produção de alimentos e reduzir o uso de defensivos agrícolas, sem causar danos ao solo e à água. Na indústria de alimentos, evidencia-se o emprego de nanofilmes para proteção e conservação dos alimentos (cor, sabor), nanosensores para verificar a deterioração dos alimentos e das embalagens com nanopartículas capazes de aumentar o tempo de vida útil dos alimentos, pois atuam como barreira contra umidade, contra micro-organismos, além de serem utilizados como agentes funcionais, ou seja, antioxidantes, corantes e conservantes. (SINGH, 2017; RESCH; FARINA, 2015).

Ainda, os nanotubos de carbono estão sendo empregados, também, na indústria petrolíferoquímica para transporte de líquidos, visto que com esses materiais é possível a construção de ductos mais leves, fortes e resistentes à corrosão. Já na indústria têxtil, a nanotecnologia é aplicada devido aos aumentos da durabilidade do produto, conforto, propriedades higiênicas e a redução do custo. 0 uso dessa tecnologia em escala nanométrica nessa área permite a confecção de materiais com funções especiais, como antibactericida, proteção contra radiação ultravioleta e antiodores. A título de exemplo, 
cita-se as nanopartículas de prata que são utilizados em meias e roupas esportivas, devido à capacidade antibacteriana e antiodorifera (SINGH, 2017).

Shah e Powers (2015) mostram que a nanotecnologia pode ser importante para o desenvolvimento de um país em relação aos recursos renováveis, como a água e energia, posto que são recursos importantes, principalmente, para a indústria de base, ou seja, a nanotecnologia pode ser mais sustentável, quando comparada ao antigo modelo produtor-consumidor adotado pelos países industrializados. A maioria das pesquisas na área de recursos hídricos envolvem materiais e processos simples e baratos, podendo ser implementados tanto nas comunidades remotas que sofrem com a escassez de água quanto nos grandes centros urbanos. Em relação à energia, existem diversos estudos baseados em nanotecnologia, voltados para o uso da energia solar, biomassa e energia eólica. A título de exemplo, cita-se o uso da técnica de fotocatálise através do uso de energia solar e nanopartículas de titânio que mineralizam alguns poluentes (SHAH; POWERS, 2015).

Os benefícios das nanotecnologias são extremamente excitantes e os nano-cientistas estão ocupados em sintetizar novos materiais e prever novas aplicações, entretanto, é crucial que também sejam pesquisados os riscos e a segurança dos nanomateriais à saúde humana e meio ambiente e como células, organismos e tecidos reagem à presença de nanopartículas, como bem argumenta Gatti (2016). Em suas pesquisas, Gatti (2014) aponta evidências clínicas da presença de nanopartículas em tecidos patológicos e no sangue que são transportadas para qualquer órgão do organismo e sem qualquer barreira para viajarem livremente. Grande parte das partículas, por não serem degradáveis por nosso organismo, não oferecem nenhuma maneira de se livrar delas. Face ao exposto, Gatti (2014) questiona: qual o destino destas nanopartículas a longo prazo? Ao responder, a pesquisadora diz que é impossível não esperar uma reação inflamatória e problemas das interações entre as nanopartículas e proteínas e entre as nanopartículas e DNA. Se alojadas no cérebro, estudos mostram que podem causar inflamações e doenças neurológicas como o Autismo, Alzheimer, Mal de Parkinson ou outras doenças. Nanopartículas podem interagir diretamente com o DNA e se a interação não é controlada, o DNA pode ser danificado e ser causa para malformações da prole (GATTI, 2014, p.1).

Portanto, as mesmas propriedades que fazem as nanopartículas tão atrativas podem ser fonte de risco, visto que o aumento da superfície em relação ao volume proporciona o aumento da reatividade, e as manifestações físico-químicas diversas das expressadas em escala maior podem ocasionar atividade biológica e toxicidade diferente das já conhecidas. Como exemplo, cita-se uma nanopartícula de $10 \mathrm{~nm}$ que tem $20 \%$ de átomos de superfície, enquanto uma nanopartícula de $1 \mathrm{~nm}$ tem 100\% de átomos de superfície, influenciando as aglomerações, dispersões e estabilização dessas partículas. Quanto menor 
o tamanho das partículas, maior a área de superfície e, consequentemente, maior atividade biológica e maior toxicidade (FOLADORI; INVERNIZZI, 2016).

Sufian et al. (2017) compartilham que os nanomateriais são novos produtos químicos e há pouca informação disponível sobre segurança e riscos para a saúde e para o meio ambiente. Para os autores, a exposição humana aos nanomateriais pode ocorrer nas diversas fases do ciclo de vida desse material, desde a síntese, a produção e a incorporação nos produtos, caracterizando a exposição ocupacional. Igualmente, a exposição humana poderá ocorrer, na utilização desses produtos, quando há a exposição do consumidor, na eliminação e, por conseguinte, acumulação no ambiente. Sufian et al. (2017) constataram que a presença dos nanomateriais no ar deve-se tanto aos processos de síntese quanto aos processos de síntese e manipulação de pós-nanomateriais, sendo a via inalatória a principal via de interação no contexto ocupacional.

Em relação à exposição via oral, Louro, Borges e Silva (2013) relatam que as nanopartículas são absorvidas, principalmente, pelo intestino, o que ocorre devido à incorporação desses materiais nos alimentos, suplementos ou embalagem de alimentos, assim como os originados da contaminação do solo ou da água (LOURO; BORGES; SILVA, 2013). Estudos em amígdalas humanas realizados por Dvorackova et al. (2009) constataram a presença de vários aglomerados de metálicos nanoestruturados provenientes da poluição ambiental que entram no organismo humano pela respiração e podem afetar a saúde humana.

Todavia, Gajewicz (2012) observa muitas contradições nas pesquisas, porquanto uma mesma nanopartícula, em alguns estudos, é relatada como altamente prejudicial aos organismos e ao meio ambiente e em outras investigações conclui-se como pouco inócua pela sua baixa toxicidade. Uma das razões para isso talvez seja a falta de normatização de dados para caracterizar a toxicidade desses nanomateriais (GAJEWICZ, 2012).

Essa também foi a conclusão encontrada pelos autores Fernandes e Waissmann (2013) ao realizarem uma revisão da literatura sobre os efeitos dos nanotubos de carbono e fulerenos sobre a pele. Eles observaram a falta de padronização da descrição das propriedades físico-químicas das nanopartículas utilizadas nos experimentos, além dos diferentes protocolos empregados, gerando dificuldades na interpretação de dados e resultados divergentes (FERNANDES; WAISSMANN, 2013).

Entretanto, estudiosos como Hankin e Caballero (2014) também se posicionam no sentido de que as nanotecnologias podem causar consequências negativas ambientais, sanitárias e de seguranças, antes que métodos adequados, baseados na análise quantitativa do risco sejam implementadas. Devido a isso, sugerem a efetivação de uma abordagem de precaução para a regulação dessa tecnologia, a fim de evitar possíveis efeitos danosos e uma reação pública. Ademais, alertam para a necessidade de abordagens regulatórias para as nanotecnologias, mas que estas sejam dinâmicas, maleáveis e 
ajustáveis, considerando os novos conhecimentos adquiridos e o entendimento dos possíveis impactos nanotecnológicos. Os especialistas na área verificaram há pouco tempo que os fatores regulatórios e da inovação podem ser integralizados. (HANKIN; CABALLERO, 2014).

A governança dos riscos é uma ferramenta estratégica para os governos e visa a reduzir os riscos dos impactos nocivos, sendo uma solução alternativa para a inovação. Uma gestão efetiva e integrada estatal deve auxiliar a concretização de benefícios, focada em alcançar tanto os fins sociais quanto a competitividade econômica. É fundamental assegurar o desenvolvimento nanotecnológico seguro e sustentável, por intermédio de uma governança efetiva que possibilitaria uma tecnologia segura e sustentável, voltada à sociedade, sem cingir a inovação, considerando a segurança, a sustentabilidade e o cumprimento das metas sociais a fonte de inovação, proporcionando um estímulo desta, para fins específicos. A governança efetiva demanda um alto nível de diálogo, colaboração, gerenciamento entre as muitas instituições e partes interessadas, englobando aquelas que desenvolvem, sintetizam, comercializam e regulamentam as nanotecnologias, bem como os representantes da sociedade civil, com o propósito de promover um processo proativo e adaptativo (HANKIN; CABALLERO, 2014).

Práticas de segurança devem fazer parte do desenvolvimento responsável nanotecnológico. A Nano Risk Framework lançou, em 2007, uma proposta de estrutura global e flexivel para avaliar os riscos possíveis das nanopartículas, com a particularidade de recomendar informações sobre o ciclo de vida, suas propriedades, ecotoxicidade e descarte. A CENARIOS ${ }^{\circledR}$ foi elaborada em cooperação com Innovation Society e a TÜV SÜD Industry Service, sendo um sistema de gestão e monitoramento de riscos para atender às necessidades específicas de avaliação de risco nanotecnológico dos trabalhadores, consumidores e meio ambiente. Já o AssuredNano ${ }^{\text {TM }}$, desenvolvido em 2008, é um sistema de acreditação da segurança de nanomateriais, relacionado com a comercialização de nanoprodutos e as preocupações com a saúde, meio ambiente e segurança do trabalhador (HANKIN; CABALLERO, 2014). Observa-se que ainda são iniciativas privadas.

Outra iniciativa inovadora de organismos privados é da plataforma Integrated Nano-Science \& Commodity Exchange (INSCX) que visa o comércio de nanomateriais por intermédio de uma plataforma de negociação de mercadorias com o diferencial de ofertar um mercado centralizado que permite uma lista completa, confiável e com certificação das exigências de qualidade e conformidade. O sistema INSCX funciona segundo as normas de autorregulação que comandam a oferta dos nanomateriais, tendo como regras as estruturas legislativas em vigor, a fim de salvaguardar o interesse mercadológico e o social. Com o INSCX é possível obter um relatório que disponibiliza o rastreamento, o uso e o ciclo de vida dos nanomateriais negociados nessa plataforma (INSCX). 


\section{A REGULAMENTAÇÃO DA NANOTECNOLOGIA NO BRASIL}

As discussões sobre a regulamentação das nanotecnologias é assunto recente na maioria dos países que desenvolvem produtos e aplicações com nanopartículas. A intenção é trazer à discussão como o Brasil está buscando regular a nanotecnologia, razão pela qual não será dado ênfase às iniciativas de regulamentação em outros países. Entende-se que é necessária uma coordenação internacional para discutir os riscos das nanotecnologias e sua regulamentação.

A título de exemplo, pode-se dizer que o empenho até o presente momento para a regulação das nanotecnologias está mais centrado em organismos não governamentais e organismos internacionais, como a Organização para a Cooperação e Desenvolvimento Econômico (OCDE), a União Europeia e as normas ISO. Na União Europeia, as discussões estão registradas no regulamento da REACH (Registro, Avaliação, Autorização e Restrição de Produtos Químicos), nos documentos da European Agency for Safety and Health at Work; OSHA; Occupational Nanotechnologies Industries Association (NIA), FDA. Nos países asiáticos conta-se com a ANF-Asia Nano Forum, com o Comitê de Medidas de Segurança para nanomateriais do Japão e com a Chinese Academy of Sciences, SAICM e International Council on Nanotechnology - ICON. Nos Estados Unidos observa-se o Ato de Controle de Substâncias Tóxicas (TSCA) e as ações do National Institute for Health(NIH) FDA (Food and Drug Administration). Contudo, até o presente momento não se verifica uma legislação global específica ou unificada para os nanomateriais, logo, os nanoprodutos são registrados nos mais variados países através das agências reguladoras específicas daquele país, sendo cada situação avaliada individualmente. (HANKIN; CABALLERO, 2014; ENGELMANN; PULZ, 2015).

A ISO atribuiu ao Comitê Técnico n²29 a responsabilidade de preparar, analisar e publicar normas relativas à nanotecnologia como sua definição (ENGELMANN; MARTINS, 2017). A União Europeia estabelece notificação compulsória para os nanocosméticos, e alguns Estados-Membros da UE, como a França, Bélgica e Dinamarca, adotaram os procedimentos de informação obrigatória para uma variedade de nanoprodutos disponíveis comercialmente (HANKIN; CABALLERO, 2014).

Destaca-se que na UE centros e instituiç̧ões públicas e privadas são responsáveis pela repercussão que seus estudos nanotecnológicos podem ocasionar ao meio ambiente e à saúde humana. Ademais, no ano de 2008, foi elaborado pela UE uma compilação de condutas para a pesquisa nas áreas da nanotecnologia e das nanociências, com a realização de revisão bienal, com o intuito de instruir os paísesmembros, pesquisadores, cientistas, financiadores de pesquisas e demais interessados para a evolução de estudos responsáveis (HUPFFER; ENGELMANN, 2017). Por sua vez, o Regulamento n 1169 de 2011 determinou o fornecimento de informação aos consumidores sobre os nanoalimentos. Esse regulamento 
trouxe uma importante inovação: os nanomateriais devem ser rotulados de forma clara na composição do produto com o prefixo "nano" entre parênteses após o nome da substância (HUPFFER; ENGELMANN, 2017).

No Brasil, o desenvolvimento da nanotecnologia é uma política pública prioritária cujo objetivo principal é angariar fundos de investimento para desenvolvimento da pesquisa e da indústria técnica nessa área, tanto para o setor público quanto para o setor privado, segundo Foladori et al. (2012). Assim como em outros países da América Latina, há duas características semelhantes identificadas nesse processo, que são a estruturação de centros de excelência incorporado à indústria e a omissão desses países quanto às questões relacionadas com a proteção do trabalhador e do consumidor frente aos possíveis riscos dessa tecnologia. Além disso, Foladori et al. (2012) ressaltam outra característica comum aos países da América Latina na estruturação da nanotecnologia nesses países, que é a ausência da participação da sociedade nas decisões de política pública.

Pereira e Fonseca (2013), em seu estudo sobre a abordagem da política de regulamentação da nanotecnologia no Brasil, observaram que o Brasil não é um exemplo de preocupação com responsabilidade na política dessa tecnologia. No Brasil, verifica-se um foco exagerado em fomentar a competitividade industrial através da pesquisa e desenvolvimento, sendo consequência de um ambiente hermético de formulação de políticas públicas, centrado na visão ingênua dos benefícios suficientes das ciências e tecnologias. Esses autores, também, analisaram que no contexto sociopolítico atual haverá obstáculos que desafiarão a efetividade de introduzir o arcabouço institucional de outros países mais avançados para as práticas de governança local. Eles sugerem, para o caso brasileiro, pesquisas focadas na expansão de nanotecnologias sociais, adequando o desenvolvimento dessa tecnologia com os problemas sociais e ambientais. (FONSECA; PEREIRA, 2013).

Como na maioria dos países, no Brasil a discussão em torno da regulamentação da nanotecnologia também não avançou. Em 2005, foi proposto o primeiro Projeto de Lei nº 5.076 de 2005, que visava regulamentar a pesquisa em nanotecnologia com a finalidade de respeitar os valores éticos e sociais do indivíduo e da família, evitando que a pesquisa nessa área tenha tendência para alguma corrente indesejável pela sociedade brasileira. Nesse projeto, há a projeção para a criação de uma Comissão Técnica Nacional de Nanotecnologia (CTNano) vinculada à Presidência da República para assessorar tecnicamente a implementação da Política Nacional de Nanossegurança com a estipulação de normas técnicas de segurança, pareceres técnicos para a proteção da saúde humana e do meio ambiente relacionados com a pesquisa, produção, consumo e descarte de produtos nanotecnológicos, ou seja, acompanhando todo o ciclo de vida desses produtos. (DUARTE, 2005). 
Além disso, esse Projeto de Lei previa a especificação de que todos os produtos nanotecnológicos tivessem rotulagem com símbolos indicando o uso dessa tecnologia e, em realce, expressões específicas: "produto da nanotecnologia", "contém matéria-prima nanotecnológica" ou "submetido a processo nanotecnológico". A fiscalização dessas atividades ficaria sob responsabilidade do Poder Público. Ademais, esse projeto previa que a União tivesse participação das receitas advindas da comercialização dos produtos gerados pelas pesquisas por ela financiadas. Seria criado o Fundo de Desenvolvimento de Nanotecnologia (FDNano) para o financiamento dessas pesquisas, o qual seria custeado com dez por cento dos recursos do Fundo Nacional de Desenvolvimento Científico e Tecnológico (DUARTE, 2005).

Essa proposta legislativa foi distribuída e analisada por três comissões distintas da Câmara Federal: a Comissão de Finanças e Tributação, Comissão de Desenvolvimento Econômico, Indústria e Comércio e a Comissão de Ciência, Tecnologia, Comunicação e Informática, sendo os pareceres dos relatores desfavoráveis, pois o Projeto de Lei seria incompatível e inadequado tanto financeira quanto orçamentariamente. Alguns fatores determinantes para a rejeição desse são: a ausência de aquiescência entre o Poder Público e o privado em como regimentar a nanotecnologia no Brasil ou, ainda, o entendimento de que o controle de risco nanotecnológico poderia impactar negativamente nos investimentos de projetos e pesquisa nessa área. Outro ponto de destaque é o controle estatal sobre o setor público e o privado, pois esse setor não teria capacidade para monitorar toda a atividade de pesquisa em nanociência no Brasil, além de esse controle afastar investimentos e procrastinar o desenvolvimento tecnológico. (BRASIL, 2005).

A relatora da Comissão de Ciência e Tecnologia, Comunicação e informática ressalta, em seu voto, que a regulamentação da nanotecnologia deve ser corretamente apreciada, devido aos potenciais riscos advindos dessa atividade para a saúde humana e o meio ambiente. Entretanto, a relatora argumenta que não é necessária uma proposta legislativa específica para a regulamentação dessa tecnologia, indicando que essa matéria estaria disciplinada legislativamente tanto em relação às proteções quanto às penalidades na Lei n ${ }^{\circ} 9.782$ de 1999, que define o Sistema Nacional de Vigilância Sanitária; na Lei nº 6.938 de 1981, que dispõe sobre a Política Nacional do Meio Ambiente; na Lei n 9.605 de 1998, que disciplina a Lei de Crimes Ambientais; e na Lei n 11.105 de 2005, que rege as normas de segurança das atividades que envolvam organismos geneticamente modificados e institui a Política Nacional de Biossegurança. Já quanto à rotulagem dos produtos nanotecnológicos, a relatora entende que por analogia poderia ser aplicado o contido no Código de Defesa do Consumidor, que é suficiente para regular a matéria (BRASIL, 2005).

Em 2013, novamente foi proposto um Projeto de Lei com o objetivo de regulamentar a rotulagem de produtos nanotecnológicos ou de produtos que fazem utilização da nanotecnologia sob o $n^{\circ} 5.133$ pelo 
Deputado Sarney Filho. Assim, como na proposição legislativa anterior, consta a previsão de rotulagem com símbolos e frases específicas alertando o uso de nanotecnologia nos produtos comercializados, devendo constar em parte principal do produto. Quando o produtor for cosmético, alimentos e fármacos, o consumidor deverá ser alertado da matéria-prima utilizada. A informação de que a matéria-prima se refere à nanotecnologia deverá estar especificado em documento fiscal, a fim de que essa informação esteja associada a ela e a acompanhe em todas as etapas da cadeia produtiva. Ademais, quanto aos alimentos e às matérias-primas obtidas a partir de animais alimentados com ração contendo nanoprodutos, estes deverão ser identificados com expressões específicas na parte principal do produto (SARNEY FILHO, 2013a).

A principal justificativa para a proposição dessa proposta legislativa é que os nanoprodutos são produtos com características diferenciadas e que a ausência de regulamentação da nanotecnologia no Brasil impacta diretamente na falta de controle de quantos produtos nanotecnológicos estão disponíveis para consumo, bem como o correto descarte desses após o uso. Ademais, alguns cientistas indicam que algumas nanosubstâncias podem causar alguns danos à saúde e ao meio ambiente. Essa nova proposição visa alinhar-se com os preceitos contidos no art. $6^{\circ}$ combinado com o art. 31 do Código de Defesa do Consumidor, que orienta que um dos direitos básicos do consumidor é a informação adequada e clara sobre os diferentes produtos e serviços, com especificação correta de quantidade, características, composição, qualidade e preço, bem como sobre os riscos que apresentem. (SARNEY FILHO, 2013a).

Entretanto, alguns críticos de entidades governamentais, como a gerente da Agência Brasileira de Desenvolvimento Industrial, criticaram esse projeto de Lei que visa a regulamentar a forma de rotulagem desses produtos, argumentando que: "Um símbolo de nanopartículas quer dizer o que para o consumidor? Um risco, um benefício? A tendência é confundi-lo ainda mais". Além disso, ela ressaltou a importância da realização de novas pesquisas sobre a nanotecnologia antes da regulamentação legislativa da matéria. Existe outro ponto relevante destacado por ela de que os cosméticos, alimentos e fármacos, antes de serem comercializados, já passam por testes indispensáveis para validação de eficácia, segurança e qualidade. (POMPEU; DOERDELEIN).

Ademais, o mesmo deputado Sarney Filho propôs o Projeto de Lei nº 6741 de 2013, com o objetivo de instituir a Política Nacional de Nanotecnologia, a pesquisa, a produção, o destino de rejeitos e o uso da nanotecnologia no país, que foi apensado ao Projeto de Lei no 5.133 de 2013, após decisão da Mesa Diretora da Câmara dos Deputados que também criou a Comissão Especial com o intuito de proferir parecer ao Projeto de Lei $n^{\circ} 6.741$ de 2013 e para que esta se destine a apreciar o Projeto de Lei $n^{\circ} 5.133$ de 2013. Assim como no primeiro projeto de lei proposto em 2005, esse tem, também, a finalidade de proteger o cidadão e o meio ambiente dos possíveis efeitos nocivos da nanotecnologia, respeitando os 
direitos constitucionais e observando o princípio da precaução. Nessa proposta legislativa, a pesquisa e o desenvolvimento de nanoprodutos deverão ser informados ao órgão responsável pela gestão da pesquisa científica que, dentro de 90 dias, deverá autorizar ou não as atividades. (SARNEY FILHO, 2013b).

Discorrendo mais sobre esse projeto legislativo observa-se que, caso a pesquisa envolva seres vivos, a aprovação prévia dessa atividade deverá ser consoante o controle de ética disposto na Lei 8.080 de 1990. A comercialização desses produtos deverá ser autorizada pelos órgãos de saúde e meio ambiente. Ainda, verifica-se que há a previsão de cobrança de taxa para fiscalização, a ser cobrada uma única vez no momento do registro, pois caberá ao poder público a fiscalização dos registros dos processos e dos produtos nanotecnológicos, vinculada ao poder econômico do requerente. Um ponto que merece destaque nessa proposição legislativa é quanto ao descarte dos nanorresíduos, os quais deverão ser descartados, conforme o art. 20 da Lei 12.305 de 2010 (Programa Nacional de Resíduos Sólidos), ou seja, serão descartados juntamente com outros resíduos industriais sem um tratamento diferenciado, desconsiderando suas características peculiares de reatividade. (SARNEY FILHO, 2013b).

Por outro lado, Engelmann e Pulz (2015) discutem, a respeito da ausência de legislação específica sobre nanotecnologia, que "existem várias áreas do Direito que trazem textos legais que poderão ser aplicados às nanotecnologias, como, por exemplo: o Código Civil, Código Penal, legislação ambiental e legislação trabalhista". Os autores também indicam o "arcabouço normativo - princípios e regras - que estão na Constituição Federal de 1988" (ENGELMANN, 2015, p. 177).

Na esfera do Ministério da Ciência, Tecnologia e Inovação (MCTI), a Portaria 245/2012 pode ser considerada a única regulamentação específica vigente até o presente momento. Essa Portaria instituiu o Sistema Nacional de Laboratórios em Nanotecnologia (SisNANO) como um dos elementos do Programa Nacional de Nanotecnologia, no âmbito da Estratégia Nacional de Ciência, Tecnologia e Inovação e associado ao Plano Brasil Maior (BRASIL, 2012). Conforme a análise dessa Portaria, do artigo segundo, realizada pelos autores Verdi, Hupffer e Jahno, pode-se observar que no Brasil os assuntos sobre a nanotecnologia estão ainda no início, relacionados com a implantação e administração. Em uma análise resumida, o inciso I tem por objetivo organizar a governabilidade para as nanotecnologias, já o inciso II planeja apoiar as empresas que atuam nessa área, enquanto que o inciso III delineia a realização do avanço científico e tecnológico. (VERDI; HUPFFER; JAHNO, 2017, p. 55).

Continuando a análise do inciso IV do artigo segundo, Verdi, Hupffer e Jahno (2017, p. 55) observam que esse inciso traz o aprimoramento da infraestrutura para o desenvolvimento da pesquisa básica e aplicada, já o inciso $\mathrm{V}$ tem o intuito de expandir os estudos e os benefícios nanotecnológicos. $\mathrm{O}$ inciso VI explora a globalização dos conhecimentos científicos, enquanto que o VII almeja qualificar o país a elaborar programas de cooperação internacional. Nesse sentido, é o inciso VIII que tenciona parcerias com 
os países do MERCOSUL e, por último, o inciso IX relaciona-se com a formação e preparação dos recursos humanos. Prosseguindo a análise da Portaria 245 de 2012, o artigo terceiro aborda sobre a elaboração e administração dos laboratórios, já o artigo quarto designa a competência do Comitê Consultivo, estabelecendo as atividades e atribuições. Imprescindivel atentar que os autores não verificaram qualquer regulamentação para a utilização das nanotecnologias quanto à ética, à gestão ambiental, o uso com precaução dessa tecnologia, além de não haver nenhuma proteção quanto à saúde laboral dos pesquisadores. (VERDI; HUPFFER; JAHNO, 2017).

Hankin e Caballero (2014) recomendaram um roteiro de ações relativas à regulamentação nanotecnológica no Brasil, fundamentados nas avaliações dos Laboratórios Estratégicos e Associados pertencentes ao Sistema Nacional de Laboratórios em Nanotecnologia. Fortalecer e continuar o envolvimento brasileiro nas atividades relevantes da OCDE e da ISSO; intensificar o relacionamento com os coordenadores dos projetos atuais e futuros da Nanosafety Cluster europeu para colaborar com as metas e objetivos relevantes para o Brasil; desenvolver um sistema de acreditação ou certificação governamental para as instituiç̧ões industriais e as de pesquisa, enquanto é planejado em sistema regulatório; e elaborar um banco de dados regulatório, semelhante aos desenvolvidos em outros países, especificando-se as informações importantes, avaliação de segurança, certificação e regulação da nanotecnologia e dos nanoprodutos brasileiros. (HANKIN; CABALLERO, 2014).

$\mathrm{Na}$ análise sobre autorregulação e a governança das nanotecnologias nos diferentes países, observou-se que não há interesse governamental em regulamentar as nanotecnologias e direcionar essa regulamentação para uma governança responsável. Grande parte da legislação que procura regulamentar essa tecnologia é de caráter privado, reproduzindo o interesse de grupos privados movidos pelas boas práticas de manipulação e inovação científica e que podem refletir na decisão de consumidores mais conscientes. Uma das dificuldades em regulamentar as nanotecnologias pelos diferentes países pode ser explicada por ser um mercado altamente promissor que segue crescendo de forma exponencial. Nenhum país quer tomar a iniciativa de impor restrições legislativas para não perder espaço no mercado. Por outro lado, como os riscos das nanotecnologias são globais, intergeracionais, transterritoriais, ao importar produtos com nanotecnologia de outros países, também se está importando os riscos e contribuindo para o desenvolvimento econômico destes países.

Acrescenta-se que regular a nanotecnologia frente ao panorama mundial de desenvolvimento exponencial de nanoprodutos e aplicações nanotecnológicas é um grande desafio para os governos e as organizações internacionais constituídas com a finalidade de proteger a preservação das futuras gerações. A autorregulamentação da nanotecnologia juntamente com os meios legislativos tradicionais baseados nas normas de comando e controle não acompanha o paradigma técnico e científico nanotecnológico, 
bem como não garante segurança de seu uso. Diante dessas dificuldades, sugere-se uma governança antecipatória, multidisciplinar e mundial, estruturada no controle dos riscos e no diálogo com os principais agentes responsáveis pela construção dos marcos regulatórios. Uma medida inicial seria a elaboração de diretrizes regulatórias entre os países da ONU para posteriormente estabelecer conjuntamente diretivas para nanoprodutos e aplicações nanotecnológicas mais seguras, inclusivas e sustentáveis ambientalmente.

No cenário atual, verificam-se produtos nanotecnológicos novos com efeitos desconhecidos e sem o desenvolvimento de uma diretriz regulatória apropriada. Além disso, observam-se discussões contrárias sobre a necessidade de regulamentar as nanotecnologias entre os cientistas e os defensores da regulação imediata. No Brasil, também, verifica-se essa situação de oposição ao tentar-se a regulamentação das nanotecnologias. Como exemplo, na Audiência Pública realizada em 25 de junho de 2015, constatou-se a resistência de algumas áreas da ciência, revelando a divisão de interesse entre duas grandes categorias: as Ciências Humanas e Sociais Aplicadas e as Ciências Exatas. Devido a isso, provavelmente, o modo mais pertinente de elaborar o marco regulatório seria utilizar alternativas legislativas, como os princípios que tem caráter normativo. Os princípios são do gênero norma jurídica em que as regras também fazem parte, aqueles tendo um limiar de abertura maior e mais flexivel do que as regras, visto que objetivam a colaboração da procura pela melhor juridicidade para o caso efetivo, devendo receber maior cuidado ao aplicá-los. (ENGELMANN, 2016).

O Direito passa por transformações, visando distanciar-se de uma visão positivista-legalista, buscando o diálogo entre as fontes do direito e outras fontes alternativas regulatório-normativas. Algumas dessas fontes que se destacam na nanotecnologia são as orientações emitidas pela OCDE, as normas ISO referentes à nanotecnologia e aos nanomateriais elaboradas pelo Comitê Técnico 229, os regulamentos realizados pelas agências reguladoras, as propostas e instruções expedidas pela NIOSH, além de outras orientações difundidas pelos Estados Unidos da América, União Europeia, entre outros. Portanto, ao valer-se de modelos privados produzidos por organizações como a Organização Mundial do Comércio (OMC), OCDE, a ISO entre outras, constata-se uma propensão de privatização do Direito. Disso, originar-se-ão três categorias de normas: a primeira composta por princípios de ordenação superior e os direitos fundamentais, posteriormente, a legislação em sentido amplo, o Direito Positivo e, por último, as diretrizes sancionadas pelos organismos e autoridades de padronização e de boas práticas. (ENGELMANN, 2016). 


\section{Considerações finais}

Em relação aos aspectos físico-químicos dos nanomateriais, observou-se que eles são fundamentais, posto que, justamente, essas propriedades que permitem novas funcionalidades aos materiais já conhecidos pelos cientistas. Pela literatura analisada, constatou-se que essas propriedades tendem a ser diferentes nessa escala, por causa do surgimento de efeitos quânticos e fenômenos de superfície, apresentando propriedades ópticas, térmicas, mecânicas diversas das de seu estado natural. Também, observou-se um efeito importante quando há a redução das partículas à escala nanométrica, que é o aumento da área superficial, devido ao aumento significativo da quantidade de átomos superficiais quando comparado com o volume total da partícula, modificando, consequentemente, sua reatividade química e sua funcionalidade.

Quanto à definição de nanotecnologia, constatou-se que não existe consenso quanto ao seu significado, sendo encontradas diferentes definições, modificando-se conforme a instituição pesquisada ou conforme a opção de cada país. Entretanto, apesar dessas diferenças, pode-se constatar que têm em comum a definição do tamanho da partícula e as diferentes propriedades que esses materiais adquirem nessa escala. Essa ausência de consenso quanto à definição de nanotecnologia e nanomateriais e, também, das características relevantes a serem consideradas para classificar uma partícula como sendo um nanomaterial demonstra a falta de informações que circundam as nanotecnologias, causando incertezas e insegurança tanto no meio acadêmico quanto na sociedade global.

Acerca da regulamentação nanotecnológica brasileira, pode-se observar que a prioridade ainda é arrecadar fundos de investimento para desenvolvimento da pesquisa e da indústria técnica nessa área. Alguns autores destacaram que o Brasil não é um exemplo de preocupação com responsabilidade na política dessa tecnologia. Ao pesquisar-se sobre projetos de lei que visam regulamentar a nanotecnologia no Brasil, constatou-se que foram três projetos de lei, sendo o primeiro de 2005, que foi arquivado, pois havia o entendimento de que o controle de risco nanotecnológico poderia impactar negativamente nos investimentos de projetos e pesquisa nessa área. Já os outros dois projetos de lei propostos em 2013 continuam em tramitação na câmara dos Deputados.

Por fim, verificou-se que a regulamentação da nanotecnologia é um dos maiores desafios a serem debatidos entre o governo e os diversos grupos de interesses brasileiros, considerando as particularidades das características físico-química dos nanomateriais, seus potenciais riscos e seu interesse comercial. Assim como ocorre a nível mundial, observou-se que, mesmo com o crescimento do comércio de nanoprodutos, a regulamentação desses produtos é praticamente inexistente, centrada mais na regulação de organismos privados. Dessa forma, no Brasil, a Portaria 245 do Ministério da Ciência, Tecnologia e Inovação (MCTI) de 2012 pode ser considerada a única regulamentação vigente até o presente momento. 


\section{REFERÊNCIAS}

AGÊNCIA BRASILEIRA DE DESENVOLVIMENTO INDUSTRIAL (ABDI). Relatório de Nanotecnologia. Relatório de Acompanhamento Setorial. Nanotecnologia na Área da Saúde, Mercado, Segurança e Regulamentação. Brasilia, 2013. Disponível em: <www.abdi.com.br/Estudo/relatorio-nanotecnologia.pdf >. Acesso em: 11 dez. 2018.

ALLIANZ CENTER OF TECHNOLOGY (ACT); OECD INTERNATIONAL FUTURES PROGRAME. Small sizes att matter: Opportunities and Risks of Nanotechnologies. Report in co-operation with the OECD Inter-

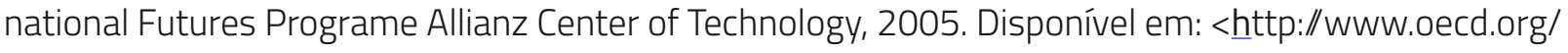
science/nanosafety/44108334.pdf>. Acesso em: 12 dez. 2018.

ALVES, Oswaldo Luiz. Nanotecnologia, nanociência e nanomateriais: quando a distância entre presente e futuro não é apenas questão de tempo. Parcerias Estratégicas. Brasilia, n.18, p. 23-40, ago. 2004. Disponivel em:<www.cgee.org.br/arquivos/pe_ 18.pdf>. Acesso em: 20 nov. 2018.

BARBOSA, Tiago Claudino; BAGATTOLLI, Carolina; INVERNIZZI, Noela. Política de Inovação em Nanotecnologia no Brasil: A trajetória dos instrumentos financeiros não reembolsáveis. Revista Tecnologia e Sociedade, v. 14, n. 31, p. 56-74, maio/agos. 2018. Disponível em: < https://periodicos.utfpr.edu.br/rts/ article/view/5970>. Acesso em: 10 dez. 2018.

BRASIL. Câmara dos Deputados. Comissão de Direito Econômico, Indústria E Comércio. Relatório do Projeto de Lei $\mathbf{n}^{\circ} \mathbf{5 . 0 7 6}$ de 2005. Relator Deputado Léo Alcântara. Brasil, Distrito Federal, 2005, passim. Disponivel em: <http://www.camara.gov.br/proposicoesWeb/fichadetramitacao?idProposicao=395948>. Acesso em: 12 dez. 2018.

BRASIL. Ministério da Ciência, Tecnologia e Inovação (MCTI). Portaria 245, de 5 de abril de 2012. Disponível em: <http://www.lex.com.br/legis_23138521_PORTARIA_N_245_DE_5_DE_ABRIL_DE_2012. aspx. >. Acesso em: 12 dez. 2018.

BUSSINGER, Elda Coelho de Azevedo; TOSE, Laura Pimenta Krause. Bioética e nanotecnologia: a moralidade como princípio orientador na busca pela formulação de marcos regulatórios aos nanocosméticos. Revista de Direito Constitucional e Internacional. v. 101, p.181-198, maio/jun. 2017. Disponível em:<http://bdjur.stj.jus/jspui/handle/2011/111121>. Acesso em: 12 dez. 2018.

COSTA, Joana Daniela da Silva. Síntese e Caracterização toxicológica de diferentes tipos de nanopartículas de Ouro. Estudos in vitro e in vivo. 2105. 150f. Dissertação de Mestrado em Controle de Qualidade da Faculdade de Farmácia da Universidade do Porto. Universidade do Porto, Porto, Portugal, 2015. Disponível em: <https://sigarra.up.pt/ffup/pt/pub_geral.show_file?pi_gdoc_id=433932>. Acesso em: 12 dez. 2018. 
DIMER, Frantiescoli A. et al. Impactos da nanotecnologia na saúde: produção de medicamentos. Química Nova, São Paulo, v. 36, n. 10, p. 1520-1526, 2013.Disponivel em: <http://www.scielo.br/scielo.phpscrip$\mathrm{t}=\mathrm{sci}$ _arttext\&pid=S010040422013001000007\&lng=en\&nrm=iso>. Acesso em: 12 dez. 2018.

DUARTE, Edson. Projeto de Lei da Câmara dos Deputados n 5.076 de 2005. (Dispõe sobre a pesquisa e o uso da nanotecnologia no país, cria Comissão Técnica Nacional de Nanossegurança - CTNano, institui Fundo de Desenvolvimento de Nanotecnologia - FDNano, e dá outras providências. Disponível em: <http://www.camara.gov.br/proposicoesWeb/fichadetramitacao?idProposicao=282392>. Acesso em: 12 dez. 2018.

DVORACKOVA J.; KUKUTSCHOVA J.; KRATOSOVA G.; ZELENIK K.; KOMINEK P.; BIELNIKOVA H. Nanopatologia: partículas nanométricas em tecidos de amigdalas humanas. Virchows Archiv, v. 455 (Suppl 1): S1-S482, p.401-4001, 2009. DOI 10.1007/s00428-009-0805-z

ENGELMANN, Wilson; PULZ, Ronei Leonardo. As nanotecnologias no panorama regulatório: entre a ausência de regulação estatal específica e a necessidade de harmonização regulatória não estatal. Revista Iberoamericana de Filosofía, Política y Humanidades, Araucária, año 17, n. 33, p. 151-181, Primer semestre de 2015. Disponivel em: <https://revistascientificas.us.es/index.php/araucaria/article/view/716 >. Acesso em: 10 dez. 2018.

ENGELMANN, Wilson. Novos Desafios para o Direito na Era das Nanotecnologias. Revista do Programa de Pós-Graduação em Sociologia: Universidade Federal de Sergipe. São Cristovão, n. 29, p. 37-54, jul./ dez., 2016. Disponível em: <https://seer.ufs.br/index.php/tomo/article/view/5976/4983>. Acesso em: 12 dez.2018.

ENGELMANN, Wilson; MARTINS, Patrícia Santos. A ISO, Suas Normas e Estruturação: Possíveis Interfaces Regulatórias. In ENGELMANN, Wilson; MARTINS, Patrícia Santos (Org.). As Normas ISO e as Nanotecnologias: entre a autorregulação e o pluralismo jurídico. 1 ed. São Leopoldo: Karywa, 2017.

FERNANDES, Ana Luiza Castro; WAISSMANN, Willian. Interações de nanotubos de carbono e fulerenos com o sistema imunológico da pele e as possíveis implicações relacionadas à nanotoxicidade cutânea. Visa em debate. Rio de Janeiro: v. 1, n. 4, p. 92-103, 2013, p. 99. Disponível em: <DOl:10.3395/vd. v1i4.107pt>. Acesso em: 12 dez. 2018.

FOLADORI, Guilllerno; FIGUEROA, Santiago; ZÁYAGO-LAU, Edgard; INVERNIZ, Noela. Características distintivas Del desatolo de lãs nanotecnologias em America Latina. Sociologias. Porto Alegre, ano 14, n. 30, maio/ago., p.330-363, 2012. Disponivel em: < www.seer.ufrgs.br/sociologias/article/download/30084/18667>. Acesso em: 12 dez. 2018. 
FOLADORI, Guillermo; INVERNIZZI, Noela. La regulación de las nanotecnologías: una mirada desde las diferencias EUA-UE. Visa em Debate. Rio de Janeiro, v.4, n. 2, p. 8-20, 2016, p. 11. Disponível em: <DOI:10.3395/2317-269x.00726>. Acesso em: 12 dez. 2018.

FONSECA, Paulo F.C; PEREIRA, Tiago Santos. The Governance of nanotechnology in the Brazilian context: entangling approaches. Technology in Society. v. 37, p. 16-27, jan. 2013. Disponívelem: <DOI: 10.1016/j. techsoc.2013.07.003>. Acesso em: 12 dez. 2018.

GATTI, Antonietta Morena. Nano-biointeraction and nanopathology. Medical Science News, Ouc. 2016. Disponivel em: <http://www.news-medical.net/news/20161031/Nano-biointeraction-and-nanopathology.aspx >. Acesso em: 10 dez. 2018.

GATTI, Antonietta Morena. Nanomedicine and Nanopathology: Two Opposite

Aspects of Nanotechnologies. Journal of Nanomedicine Research, v.1, n. 2, p. 1-2, 2014. Disponivel em: <https://medcraveonline.com/JNMR/JNMR-01-00008.pdf>. Acesso em: 10 dez. 2018.

GLOBAL SALES OF NANOMATERIALS (INSCX). Suppliers of Nanomaterials - Online Ordering for Delivery Worldwide. Disponivel em: <https://inscx.com/shop/>. Acesso em: 12 dez. 2018.

HANKIN, Steve M.; CABALLERO, Nelson Eduardo Durán. Regulação da Nanotecnologia no Brasil e na União Europeia. Diálogos Setoriais União Europeia - Brasil. Brasília: MCTI, 2014. Disponível em: <http:/l sectordialogues.org/sites/default/files/acoes/documentos/dialogos_setoriais__nanotecnologia_portugues.pdf>. Acesso em: 12 dez. 2018.

HUPFFER, Haide Maria; ENGELMANN, Wilson. As Nanotecnológicas: entre Autorregulação e Governança. ENGELMANN, Wilson; HUPFFER, Haide Maria (Org.). Impactos Sociais e Jurídicos das Nanotecnologias. 1.ed. São Leopoldo: Casa Leiria, 2017. Disponivel em E-Book.

INTERNACIONAL RISK GOVERNANCE COUNCIL (IRG). Appropriate Risk Governance Strategies for Nanotechnology Application in Food and Cosmetics. Genebra, 2009. Disponivel em: <http://www.irgc.org/ IMG/pdf/irgc_nanotechnologies_food_and_cosmetics_policy_brief.pdf>. Acesso em: 12 dez. 2018.

LOOS, Mário Rodrigo. Nanociência e nanotecnologia: Compósitos Termofixos Reforçados com Nanotubos de Carbono. 1. ed. Rio de Janeiro: Interciência, 2014.

LOURO, Henriqueta; BORGES, Teresa; SILVA, Maria João. Nanomateriais manufaturados: novos desafios para a saúde pública. Revista Portuguesa Saúde Pública. Lisboa, v. 31, n. 2, p. 145-157, dez, 2013, p. 147. Disponivel em:<http://dx.doi.org/10.1016/j.rpsp.2012.12.004 >. Acesso em: 12 dez. 2018.

MARCONE, Glauciene Paula de Souza. Nanotecnologia e Nanociências: Aspectos Gerais, Aplicações e Perspectivas no Contexto do Brasil. Perspectivas da Ciência e Tecnologia. v. 7. n. 2, Rio de Janeiros, 
2015. Disponível em: <http://revistascientificas.ifrj.edu.br:8080/revista/index.php/revistapct/article/ view/588/377>. Acesso em: 12 dez. 2018.

MARTINEZ, Diego Stéfani Teodoro; ALVES, Oswaldo Luiz. Interação de Nanomateriais com Biossistemas e a Nanotoxicologia: na Direção de uma Regulamentação. Ciência e Cultura. São Paulo, v. 65, n. 3, p. 32-36, jul. 2013. Disponivel em: <http://cienciaecultura.bvs.br/scielo.php?script=sci_arttext\&pi$d=S 000967252013000300012 \&$ lng=en\&nrm=is>. Acesso em: 12 dez. 2018.

MEDEIROS, Eliton S.; Paterno, Leonardo G.; MATTOSO, Luiz Henrique Capparelli. Nanotecnologia. In: DURAN, Nelson; MATTOSO, Luiz Henrique Capparelli; MORAIS, Paulo Cezar (Org.). Nanotecnologia: Introdução, preparação e caracterização de nanomateriais e exemplos de aplicação. 1. ed. São Paulo: Artliber, 2006.

NATIONAL NANOTECHNOLOGY INITIATIVE (NNI). Nanotechnology: Big Things from a Tiny Word. Jul. 2008. Disponivel em <http:/www.nano.gov/node/240>. Acesso em: 12 dez. 2018.

POMPEU, Carolina; DOERDELEIN, Natália. Deputado e Gerente da ABDI discordam sobre alerta de uso de nanotecnologia. Disponivel em: <http://www2.camara.leg.br/camaranoticias/noticias/INDUSTRIA-E-COMERCIO/457489-DEPUTADO-E-GERENTE-DA-ABDI-DISCORDAM-SOBRE-ALERTA-DE-USO-DE-NANOTECNOLOGIA.html>. Acesso em: 12 dez. 2018.

RESCH, Sibelly; FARINA, Milton Carlos. Mapa do Conhecimento em nanotecnologia no setor agroalimentar. Revista de Administração Mackenzie. São Paulo, v. 16, n. 3, p. 51-75, maio/jun., 2015. Disponível em: <http://dx.doi.org/10.1590/167869712015/administracao.v16n3p51-75>. Acesso em: 20 set. 2018.

ROCO, Mihail C.; HARTHORN, Barbara; GUSTON, David; SHAPIRA, Philip. Innovative and responsible governance of nanotechnology for societal development. Journal of Nanoparticle Research. Santa Barbara, v. 13. p. 3557-3590. set, 2011. Disponível em: <doi: 10.1007/s11051-011-0454-4>. Acesso em: 20 set. 2018.

SARNEY FILHO, José (2013a) Projeto de Lei da Câmara n 5.133 de 2013. Regulamenta a rotulagem de produtos da nanotecnologia e de produtos que fazem uso da nanotecnologia. Disponível em: <http:// www.camara.gov.br/proposicoesWeb/fichadetramitacao?idProposicao=567257>. Acesso em:20 set. 2018.

SARNEY FILHO, José (2013b) Projeto de Lei nº $\mathbf{6 . 7 4 1}$ de 2013. Dispõe sobre a Política Nacional de Nanotecnologia, a pesquisa, a produção, o destino de rejeitos e o uso da nanotecnologia no país. Disponível em: <http://www.camara.gov.br/proposicoesWeb/prop_mostrarintegra;jsessionid=9F307FA406E4B447D70C749B8E5B45DA. proposicoesWebExterno2?codteor=1177566\&filename=Tramitacao-PL+6741/2013>. Acesso em: 20 set. 2018. 
SHAH, Ismat S; POWERS, Tomas M. Nanotechnology-A parth forward for developing nations. Materials Science and Engineering. n. 92, 2015. Disponivel em: <doi:10.1088/1757-899X/92/1/012001>. Acesso em: 24 set., 2018.

SHATKIN, Jo Anne. Nanotechnology: Health and Environmental Risks.20 ed. Boca Raton: CRC Press, Taylor \& Francis Group, 2013.

SINGH, Namita Ashish. Nanotechnology Innovations, Industrial Applications and Patents. Environmental Chemistry Letters. v. 15, p. 185-191, 2017. Disponivel em: <DOI 10.1007/s10311-017-0612-8>. Acesso em: 19 set. 2018.

SUFIAN, Mian Muhammad et al. Safety issues associated with the use of nanoparticles in human body. Photodiagnosis and Photodynamic Therapy. v. 19, p. 67-72, 2017, p. 68. Disponível em: <http://dx.doi. org/10.1016/j.pdpdt.2017.05.012>. Acesso em: 12 dez. 2018.

StatNano. 2017a.Top Ten Countries in Nanotechnology Patents in 2017. NanotechnologyProducts. Data Base (StatNano), 04 mar., 2018. Disponivel em: <http://statnano.com/news/62082 >. Acesso em: 21set. 2018.

StatNano. 2017b. Publication of More Than Half of the Nanotechnology Articles of 2017 by the top there Countries. NanotechnologyProducts. Data Base (StatNano), 07 jan. 2018. Disponivel em: <http://statnano.com/news/61353>. Acesso em: 12 dez. 2018.

StatNano. 2017c. Ranking of Countries in Nanotechnology Publications in 2016. NanotechnologyProducts. Data Base (StatNano), 04 Jan., 2017. Disponível em: <http://statnano.com/news/57105>. Acesso em: 12 dez. 2018.

STATNANO. 2018. Nanotechnology Products Database (StatNano). Introduction. Disponivel em: <http:// product.statnano.com/>. Acesso em: 12 dez. 2018.

VERDI, Roberta; HUPFFER, Haide Maria; JAHNO, VanuscaDalosco. Desvendando o universo da nanotecnologia: dialogando sobre riscos, benefício e uma nova ética para a civilização tecnológica. In: ENGELMANN, Wilson; HUPFFER, Haide Maria. BioNanoÉtica: Perspectivas Jurídicas. 1. ed. São Leopoldo: Trajetos Editorial, 2017.

ZARBIM, Aldo J. G. Química de (Nano)materiais. Química Nova. São Paulo, v. 30, n. 6, p. 1469- 1479, nov./dez. 2007, p. 1473. Disponivel em: <http://www.scielo.br/scielo.php?script=sci_arttext\&pi$d=$ S0100-40422007000600016>. Acesso em: 21 set. 2018 